Article

\title{
High-Throughput Screening of Chlorella Vulgaris Growth Kinetics inside a Droplet-Based Microfluidic Device under Irradiance and Nitrate Stress Conditions
}

\author{
Marwa Gamal Saad ${ }^{1,2, *}$, Noura Sayed Dosoky ${ }^{3, *} \mathbb{0}$, Muhammad Shuja Khan ${ }^{4}{ }^{\mathbb{D}}$, \\ Mohamed Shafick Zoromba ${ }^{5,6}$, Laila Mekki ${ }^{7}$, Magdy El-Bana ${ }^{2}$, David Nobles ${ }^{8}$ and \\ Hesham Mohamed Shafik ${ }^{2}$ \\ 1 Department of Electrical and Computer Engineering, Texas A\&M University, College Station, TX 77843, USA \\ 2 Department of Botany, Faculty of Science, Port Said University, Port Said 42521, Egypt \\ Department of Chemistry, University of Alabama in Huntsville, Huntsville, AL 35899, USA \\ 4 Department of Electrical and Computer Engineering, University of Alabama in Huntsville, Huntsville, \\ AL 35899, USA \\ 5 Chemical and Materials Engineering Department, King Abdulaziz University, Rabigh 21911, Saudi Arabia \\ 6 Department of Chemistry, Faculty of Science, Port-Said University, Port Said 42521, Egypt \\ 7 Department of Botany, Faculty of Science, Suez Canal University, Ismailia, Egypt \\ 8 UTEX Culture Collection of Algae, College of Natural Sciences, University of Texas at Austin, Austin, \\ TX 78712, USA \\ * Correspondence: marwa.aly@sci.psu.edu.eg (M.G.S.); nouradosoky@gmail.com (N.S.D.); \\ Tel.: +1-979-985-8091 (M.G.S.); +1-256-457-0135 (N.S.D.)
}

Received: 8 May 2019; Accepted: 11 July 2019; Published: 12 July 2019

check for updates

\begin{abstract}
Biodiesel is an eco-friendly renewable fuel that can be derived from microalgae. Maximization of biomass and lipid productivities are considered the main challenges for algal biodiesel production. Since conventional batch cultures are time-, space-, and reagent-consuming with many restrictions to apply many replicates, microfluidic technology has recently emerged as an alternative low-cost and efficient technology with high throughput repeatability and reproducibility. Different applications of microfluidic devices in algal biotechnology have been reported, including cell identification, sorting, trapping, and metabolic screening. In this work, Chlorella vulgaris was investigated by encapsulating in a simple droplet-based micro-array device at different light intensities of 20,80 , and $200 \mu \mathrm{mol} / \mathrm{m}^{2} / \mathrm{s}$ combined with different nitrate concentrations of $17.6,8.8$, and $4.4 \mathrm{mM}$. The growth results for $C$. vulgaris within microfluidic device were compared to the conventional batch culture method. In addition, the effect of combined stress of deficiencies in irradiance and nitrogen availability were studied to illustrate their impact on the metabolic profiling of microalgae. The results showed that the most optimum favorable culturing conditions for Chlorella vulgaris growth within the microfluidic channels were $17.6 \mathrm{mM}$ and $80 \mu \mathrm{mol} / \mathrm{m}^{2} / \mathrm{s}$.
\end{abstract}

Keywords: Chlorella vulgaris; biodiesel; droplet-based microfluidic device; conventional batch cultures; light; nitrate; biomass productivity

\section{Introduction}

Microalgae are photosynthetic organisms and a promising feedstock for different products, such as antibiotics, cosmetics, toothpastes, alginates, agar [1-3], and renewable fuels, e.g., biodiesel, biohydrogen, and bioethanol [4,5], because they conserve water and land resources [6]. They can also be used as biofertilizers and bioremediators [7]. The history of using algae as a renewable energy feedstock dates back to the 1970s [4]. The main challenges for algae production are maximizing biomass and 
lipid productivities by optimizing culture and production conditions which are considered to be time and labor extensive. Different factors affect biomass and the behavior of algal cells [8]. These factors are species-specific and can be categorized into three groups: biological, chemical, and physical factors. Biological factors are species size, shape, age, and cell composition, while chemical factors include nutrients concentrations and availability, C:N and N:P ratios, and the physical factors cover light, temperature, and $\mathrm{pH}$ [9]. Testing multiple growth factors simultaneously provides multidimensional information on factors affecting the growth. Among those, photon flux and nitrogen availability are important factors that influence algal growth and its behavior over a period of time.

Chlorella vulgaris (C. vulgaris) is a eukaryotic unicellular chlorophyte [10]. It has been cultured for various commercial applications, like antioxidants, human nutrition, and bioremediation [11-13]. C. vulgaris was also cultured as a model strain for biofuel production in the U.S. and Europe [6]. Further, C. vulgaris can adapt to extreme conditions, such as $10-15 \% \mathrm{CO}_{2}$ vol. \% [14], high temperature [15], acidic $\mathrm{pH}$ [16], and up to 200 and $50 \mathrm{ppm}$ of $\mathrm{NO}$ and $\mathrm{SO}_{2}$, respectively [14]. Traditional batch cultures have been used previously which provide appropriate biomass for fatty acid profiles, proteins, and carbohydrate analyses. However, they exhibit numerous disadvantages, such as limited numbers of replicates, restricted limits of testing factors, and are space-, reagent-, and time-consuming [17]. On the other hand, there has been tremendous interest recently to utilize microfluidic devices as a tool to investigate the microalgae under different conditions.

C. vulgaris has been tested inside microfluidics with different designs for a variety of purposes [18-22]. A microfluidic device (lab-on-a-chip) offers the capability to manipulate a very small volume of fluids; $10^{-6}$ to $10^{-18} \mathrm{~L}$ through connected microchannels with dimensions from 10 to $100 \mu \mathrm{m}$ [23]. This reveals tremendous miniaturization capabilities and enables innovative ways of performing biotests without the need for conventional laboratory infrastructure [5]. Poly dimethylsiloxane (PDMS) is the most popular polymer used for device fabrication especially for biological and chemical samples. PDMS is the most popular polymer used for device modeling because it is inexpensive, transparent, and biocompatible [23,24]. It further prevents solution evaporation for a certain time [25], and is more appropriate for analyses of biological and chemical samples than glass and silicon with faster prototyping and the possibility of electrosensing [26].

In this work, a microfluidic device capable of simultaneously testing different culture conditions using a single system design is presented. The design is based on creating separated channels parallel to each other. Each of these channels can be loaded with a different solution of nitrate concentration of $17.6,8.8$, and $4.4 \mathrm{mM}$. In addition, we sought to determine the feasibility of using the device as a monitoring tool in place of conventional batch techniques. We characterized the relationship between the availability of light and nitrate with the growth of $C$. vulgaris cells using both conventional culturing techniques and microfluidic techniques.

\section{Materials and Methods}

\subsection{Droplet-Based Microfluidic Design}

The droplet-based device was consisting of four parallel microfluidic devices (Figure 1). Each device was comprised of serpentine channels which were separated by a distance of about $160 \mu \mathrm{m}$. Four devices were located beside each other horizontally and the samples were processed simultaneously with constant flow rate. Inputs were used to facilitate droplet generation with one output for the waste. The two inputs were presented as two inlet channels: a $200 \mu \mathrm{m}$ wide channel for the carrier oil and a $160 \mu \mathrm{m}$ wide channel for the cell suspension. Channels had narrower width compared to the utilized droplet size to slightly squeeze the droplets to maintain consistent space between neighboring droplets. This provides precise droplet ordering for time-course growth analysis of the same droplet, and further prevents unexpected droplet merging throughout the culturing period [18]. 


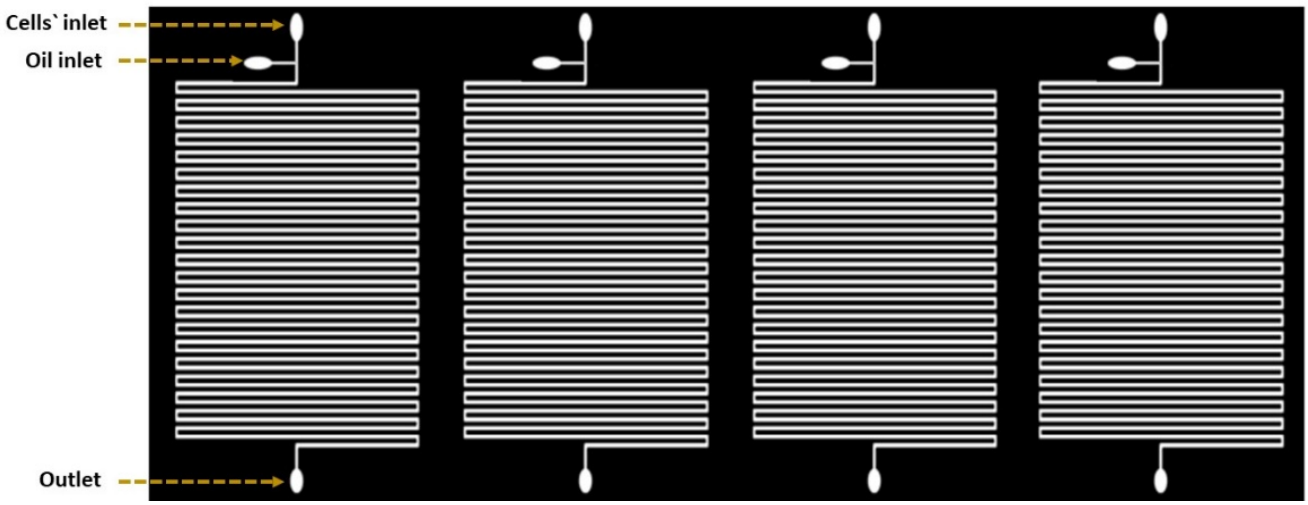

Figure 1. Schematic diagram of the microfluidic device design. The design is based on creating separated channels parallel to each other. Each of these channels can be loaded with a different solution.

\subsection{Device Fabrication}

The design of the device was performed using SOLIDWORKS ${ }^{\circledR}$ software (SolidWorks Corp., Waltham, MA, USA). The design was patterned on a silicon wafer surface with SU-8 photoresist (SU-8 2075, Microchem Corp., Westborough, MA, USA) using a conventional photolithography process then coated with the surfactant (tridecafluoro-1,1,2,2-tetrahydrooctyl) trichlorosilane (United Chemical Technologies, Inc., Bristol, PA, USA) to facilitate PDMS release from the master molds. Afterwards, the fabrication process ended with PDMS molding. PDMS layer with a thickness of $4 \mathrm{~mm}$ were bonded with a glass slide of $50.8 \times 9.0 \times 76.2 \mathrm{~mm}$ by oxygen plasma treatment. After assembly, PDMS devices were loaded with Aquapel (Pittsburgh Glass Works LLC., Pittsburgh, PA, USA) to generate hydrophobic properties inside channels' surfaces to stabilize droplets.

\subsection{Species Preparation}

A freshwater C. vulgaris was isolated from Port Said, Egypt. The species was purified on a solidified BG11 medium [27]. C. vulgaris was examined for early identification using binocular light microscope (SME-F4D, Rating: $85 \mathrm{~V}$ to $265 \mathrm{~V}, 50 / 60 \mathrm{~Hz}$, Halogen lamp: $60 \mathrm{~V} 20 \mathrm{~W}$, delay-action fuse: $1 \mathrm{~A}$ ). Axenic culture was prepared using antibiotic assessment technique. One capsule of Chloramphenicol was dissolved in $10 \mathrm{~mL} \mathrm{70 \%} \mathrm{ethanol} \mathrm{(capsule,} \mathrm{MEHTA,} \mathrm{India)} \mathrm{then} \mathrm{added} \mathrm{to} \mathrm{the} \mathrm{culture} \mathrm{which} \mathrm{left}$ to grow for two days then samples were streaked on nutrient agar medium for the confirmation of culture free-bacteria. Axenic colonies were cultured in $10 \mathrm{~mL}$ BG11 medium for five days at $20^{\circ} \mathrm{C}$ and $80 \pm 0.13 \mu \mathrm{mol} / \mathrm{m}^{2} / \mathrm{s}$ with continuous lighting. The culture volume was gradually increased per two weeks by $10 \%(v / v)$ to maintain cells. These cultures were used as stock cultures for next experiments. All steps were done under aseptic conditions. Purified samples were examined using Olympus ${ }^{\circledR}$ microscope with magnification power of $400 \times$.

\subsection{Species Identification}

C. vulgaris was identified using the $23 \mathrm{~S}$ rRNA gene. Genomic DNA was purified as previously described [28]. The quality and quantity of purified DNA was assessed using a NanoDrop ${ }^{\circledR}$ (ND-1000 UV-Vis Spectrophotometer, USA). The 23s rDNA was amplified by PCR, as described previously [29], using Platinum Taq DNA polymerase (2700 Applied Biosystems, Gene Amp ${ }^{\circledR}$, Singapore) and 40-100 ng of genomic DNA per $100 \mu \mathrm{l}$ reaction. PCR conditions were as follows: initial denaturation at $94^{\circ} \mathrm{C}$ for $2 \mathrm{~min}$, followed by 40 cycles at $94{ }^{\circ} \mathrm{C}$ for $30 \mathrm{~s}, 55^{\circ} \mathrm{C}$ for $1 \mathrm{~min}$, and $72{ }^{\circ} \mathrm{C}$ for $2 \mathrm{~min}$ with a final extension at $72{ }^{\circ} \mathrm{C}$ for $7 \mathrm{~min}$ followed by a hold at $4{ }^{\circ} \mathrm{C}$. Two $23 \mathrm{~S}$ rDNA primers were included, 23U1 (5'-AGG GGT AAA ACA CTA TTT CG-3') and $23 \mathrm{U} 2$ (5'-CCT TCT CCC GAA GTT ACG-3') [29]. Sanger DNA sequencing was performed by the University of Texas DNA sequencing facility using Applied Biosystems 3730/3730XL DNA Analyzers and BigDye Terminator v3.1 chemistry according to 
facility protocols. Bioinformatics analysis of the amplified sequence was performed by comparing similar sequences on the NCBI database via BLAST (Figure 2).

\begin{abstract}
GTTTCGGTGCGGGCTGCGAAAGCGGTACCAAATCGTGGCAAACTCTGAATACTAGATATGCTATTTATGGGCCAGTGAGACAGTGGGGGATAAGCTTCAT GTCGAGAGGGAAACAGCCCAGATCACTAGCTAAGGCCCCAAAATGATCGTTAAGTGACAAAGGAGGTGAGAATGCTGAAACAACCAGGAGGTTTGCTA GAAGCAGCCACCCTTTAAAGAGTGCGTAATAGCTCACTGGTGGAGCGTTCTTGCGCCGAAAATGTCCGGGACTAAATGATCTGCCGAAGCTGTGGGATAT TTCTAAAATATCGGTAGGGGAGCGTTCTGCTGTAGGGTGAAGCAATGATGTAAGTCATTGTGGACGAAGCGGAAGTGAGAATGTCGGCTTGAGTAACGCA AACATTGGTGAGAATCCAATGCCCCGAAAACCTAAGGATTCCTCCACTAGGTTCGTCCATGGAGGGTGAGTCAGGACCTAAGGCAAGGCCGAAAGGCGT AGTCGATGGAAAACAGGTTAATATTCCTGTACTATTTGCTGTTTGGTACCGAGGGACGGAGCAGGCAGAGATTGGCCGATATTGGATTTCGGTGGAAACTT TCGACACGGTGAGAGGTAGAAGAAAAACTAACCTTGAGTGAAGAAGTGATACGTCTCTATCTTTGGATAGAGATCAGTTGACTGTCATACTCCCAAGAAA AGCTCGAACTACTGTAAAACATCAAATACCTGTACCGTAAACCGACACAGGTGGGTTAGTAGAGTATACTAAGGGGCGCGAGATAACTCTCTCTAAGGAAC TCGGCAAAATGACCCCGTAACTNC
\end{abstract}

Figure 2. The $23 \mathrm{~S}$ rRNA gene of Chlorella vulgaris sequences in the NCBI using GeneDoc. The isolated strain was identified as Chlorella vulgaris according to the morphological characterization and molecular methods. The Basic Local Alignment Search Tool (BLAST) result of the amplified sequence with other Chlorella strains in The National Center for Biotechnology Information (NCBI) showed 98\% sequence similarity to the $23 \mathrm{~S}$ small subunit rRNA of Chlorella species.

\title{
2.5. Droplet Generation
}

Cell suspension of $C$. vulgaris with concentration of $2002 \pm 20.3 \times 10^{4}$ cells $/ \mathrm{mL}$ was loaded to $1 \mathrm{~mL}$ syringe. The carrier oil; 3M $\mathrm{M}^{\mathrm{TM}}$ Fluorinert ${ }^{\mathrm{TM}}$ Liquid FC-40 oil (Maplewood, MN, USA) with $2.5 \%$ surfactant (008-FluoroSurfactant, Ran Biotechnologies, MA, USA) was loaded to another $1 \mathrm{~mL}$ syringe. Syringes were connected separately to the channels' inlets using tubing. The flow of fluids inside syringes were automatically controlled using Fusion Touch 400 pump (Chemyx Inc., Stafford, TX, USA). As described previously [30], the $270-\mu \mathrm{m}$ droplets were generated by consistently flowing cell suspension and oil with flow rates of 150 and $300 \mu \mathrm{L} / \mathrm{h}$, respectively [31]. After $5 \mathrm{~min}$, approximately 100 uniform droplets were captured inside each channel. Most droplets had one to three cells. Droplets maintained in that device without reported merging issues for monitoring growth. Each channel in the device was loaded with different sodium nitrate concentration of 17.6, 8.8, and 4.4 mM. After loading all channels with samples, different devices were subjected to different light intensity of $20 \pm 0.31$, $80 \pm 0.37$, and $200 \pm 0.39 \mu \mathrm{mol} / \mathrm{m}^{2} / \mathrm{s}$ using LED lamps with $100 \mathrm{w}$ and $6500 \mathrm{~K}$ at $20{ }^{\circ} \mathrm{C}$.

\subsection{Traditional Batch Cultures}

Inoculations were prepared by adding a biomass concentration of $1128 \pm 24 \times 10^{4}$ cell/mL to $10 \mathrm{~mL}$ of BG11 medium. BG11 medium with different sodium nitrate concentrations of $17.6,8.8$, and $4.4 \mathrm{mM}$ were examined. Each set of nitrate cultures was tested under different light intensity of $20.88 \pm 1$, $80.17 \pm 1$, and $200.4 \pm 1 \mu \mathrm{mol} / \mathrm{m}^{2} / \mathrm{s}$ at $20^{\circ} \mathrm{C}$.

\subsection{Growth Assay Inside Droplets}

Tracking the growth of $C$. vulgaris cells encapsulated inside the same droplet in the culture channels allowed a time-course growth analysis, where the growth of cells was characterized by chlorophyll autofluorescence intensity per unit area. At scheduled analysis periods, each device was moved to the Zeiss Axio Observer Z1 microscope (Carl Zeiss MicroImaging, LLC) stage to be imaged separately. The microscope was equipped with a digital camera (Orca Flash2.8 CMOS Camera) and a filter set (excitation: $460-500 \mathrm{~nm}$, emission $>600 \mathrm{~nm}$ ). The tiles were set and marked to locate each channel during imaging. The lenses were set on powers of $10 \times 5$. 
The resulted fluorescent intensity of cells was analyzed using ImageJ software [31]. The maximum growth rate was calculated using the following equation [32]:

$$
\mu\left(\mathrm{d}^{-1}\right)=\ln (\mathrm{N} 2-\mathrm{N} 1) / \mathrm{T} 2-\mathrm{T} 1
$$

where $\mathrm{N} 2$ andN1 are the chlorophyll intensity at the times $\mathrm{t} 2$ and $\mathrm{t} 1$, respectively. The linear relationship between the cell number/droplet (count/mL) and the relative fluorescent intensity was investigated. Cell number/relative fluorescent intensity equations are as follows:

$$
\begin{aligned}
& Y=5.594 X \\
& R^{2}=0.9949
\end{aligned}
$$

where $\mathrm{Y}$ is the relative fluorescent intensity (a.u.) and $\mathrm{X}$ is the cell number/droplet (count $/ \mathrm{mL}$ ). The results are presented as the cell number per droplet for 10 replicates and standard deviation was considered.

\subsection{Growth Assay for Traditional Batch Cultures}

At constant times, cultures were well-shaken then $10 \mu \mathrm{L}$ of representative samples were loaded in a hemocytometer and counted in four $16 \times 16$ squares using Nikon light microscopy [33]. Then the summation of cells was multiplied by $10^{4}$ to estimate the cell number per mL. Two replicates were counted for each sample and the standard deviation were considered.

\section{Results and Discussion}

Nitrogen is important for DNA, protein, enzyme, and membrane synthesis. Nitrate $\left(\mathrm{NO}_{3}{ }^{-}\right)$and ammonia $\left(\mathrm{NH}_{4}+\right)$ are the most common nitrogen forms which algae can uptake [34]. The impact of the nitrogen regime on the growth and fatty acids profiles of Desmodesmus quadricaudatus and Chlorella sp. has been studied [35]. Further, the growth of $C$. vulgaris has also been significantly enhanced with an increase in light intensity as reported elsewhere [36-38]. There are a few other reports published on the metabolic profiling of microalgae cultivated under the combined stress of deficiencies in irradiance and nitrogen availability [39]. Optimum cultivation and production conditions are species-specific [40].

A simple droplet-based platform was used to simultaneously investigate the effect of different culture conditions (light intensity and nitrate availability) on the growth of $C$. vulgaris. The chlorophyll autofluorescence was initially induced using pulse-amplitude-modulating fluorometry, then correlated to carbon dioxide assimilation [41]. It is based on the energy of the absorbed photon by the chlorophyll molecule. That energy will be either used to drive the electron transfer in photosystem II with an opened reaction center or to excite the fluorescence under low light intensities. With increasing the light intensity, the reaction center of photosystem II will close, the electron transfer will cease, and the fluorescence will rise. Relationship between light over time (A) and relation between uniform area $\left(\mathrm{cm}^{2}\right)$ and light intensity $\left(\mu \mathrm{mol} / \mathrm{m}^{2} / \mathrm{s}\right)(B)$ are shown in Figure S1. Therefore, the observation of chlorophyll autofluorescence's induction with its relationship to reactions' efficiency inside photosystem II provides a rapid and non-destructive method to quantify the quantum yield of photosynthesis [42].

Growth of Chlorella vulgaris was observed over the period of time at different light intensities $\left(20,80\right.$, and $\left.200 \mu \mathrm{mol} / \mathrm{m}^{2} / \mathrm{s}\right)$ and different nitrate conditions $(17.6,8.8$, and $4.4 \mathrm{mM})$ using both the conventional batch cultures (Figure 3 ) and the microfluidic device (Figure 4). The results for $C$. vulgaris culture growth was significant in both techniques within three days of cultivation. The growth was increased with an increase in the concentration of the nitrate and the light intensity. However, the growth behavior of $C$. vulgaris suspended in the regular batch culture showed that the growth was limited at $20 \mu \mathrm{mol} / \mathrm{m}^{2} / \mathrm{s}$ for all nitrate concentrations, whereas $80 \mu \mathrm{mol} / \mathrm{m}^{2} / \mathrm{s}$ was reported to be the optimum light intensity conditions for $C$. vulgaris growth. Experimental data shown in Figure 3 were collected up to $72 \mathrm{~h}$ and C. vulgaris suspended in BG11 medium inside $270 \mu \mathrm{m}$ droplets did not show being static with in the microfluidic channels. However, these experiments could be extended for a 
longer period of time if required as the microdroplets can also be used for a longer time period for continuous monitoring.
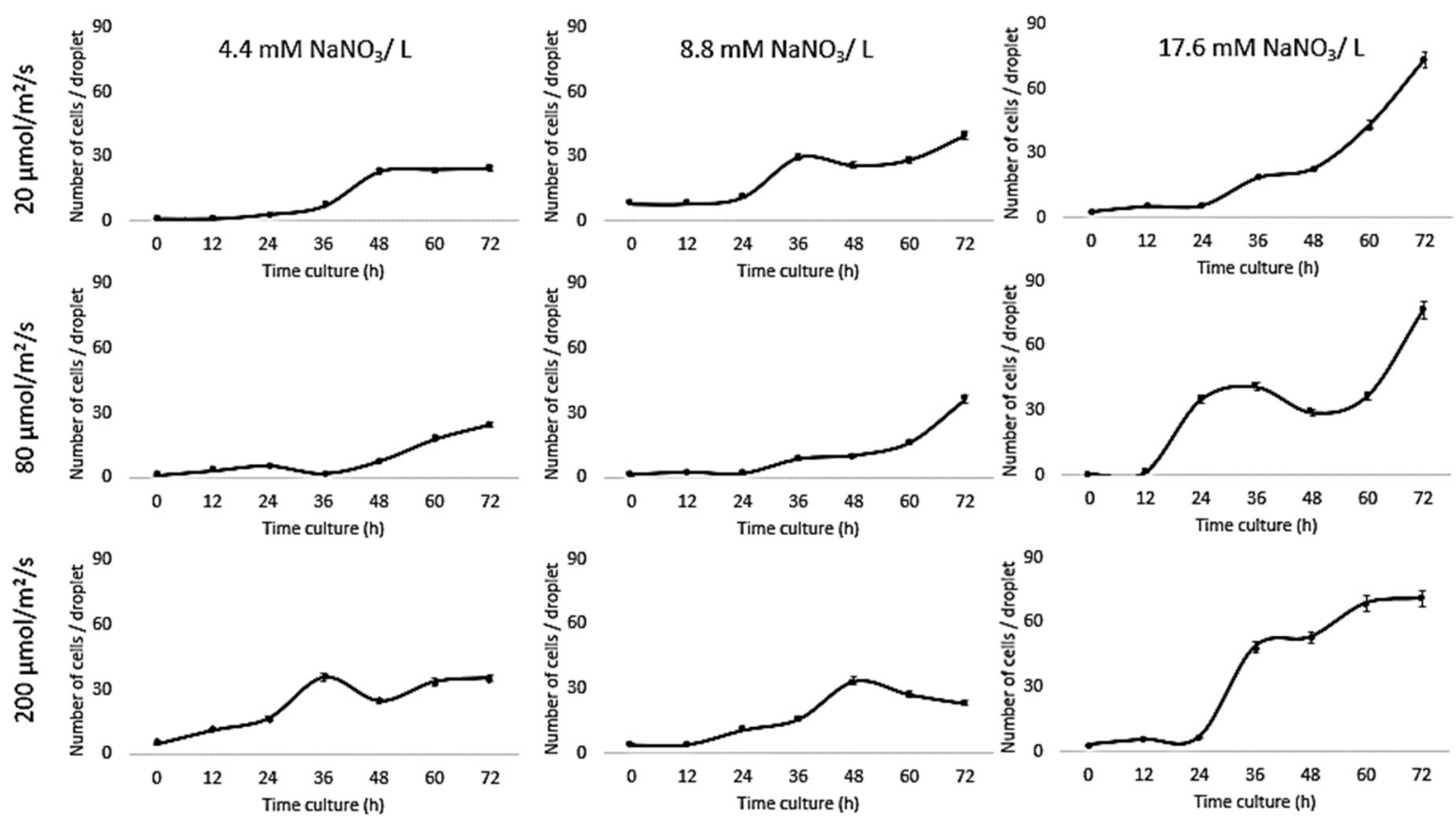

Figure 3. Droplet-based microfluidic technique. Growth kinetics as cell number (count/droplets) for C. vulgaris cells suspended in BG11 medium with different nitrate concentrations $(4.4,8.8$, and $17.6 \mathrm{mM})$ inside $270 \mu \mathrm{m}$ droplets for 3 days at $20^{\circ} \mathrm{C}$ and different light intensities $\left(20,80\right.$, and $\left.200 \mu \mathrm{mol} / \mathrm{m}^{2} / \mathrm{s}\right)$. Standard deviation was applied $(\mathrm{n}=10)$.
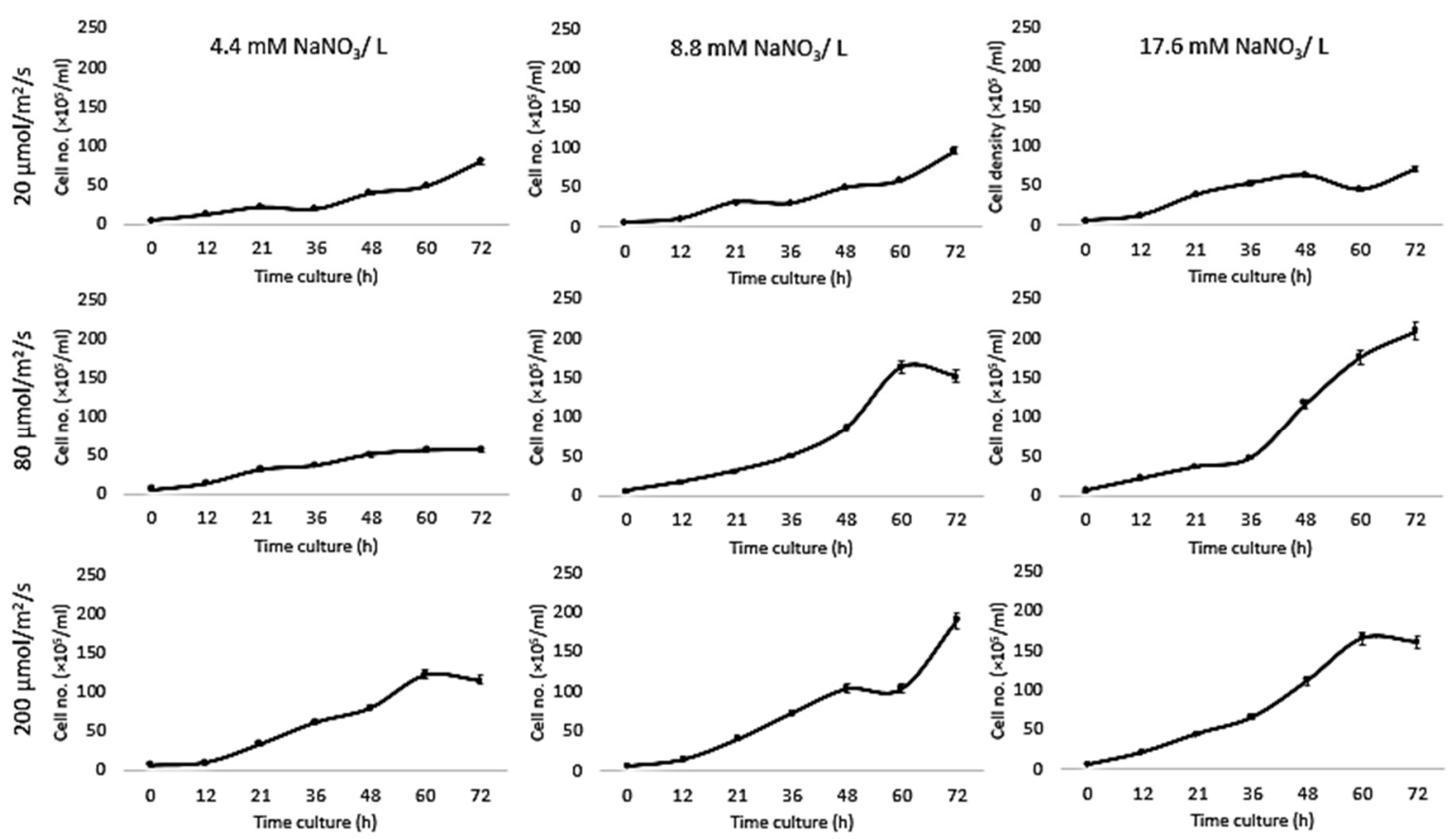

Figure 4. Traditional culture results. Growth kinetics as cell number (count/droplets) for C. vulgaris cells suspended in BG11 medium with different nitrate concentrations $(4.4,8.8$, and $17.6 \mathrm{mM})$ for 3three days at $20^{\circ} \mathrm{C}$ and different light intensities $\left(20,80\right.$, and $\left.200 \mu \mathrm{mol} / \mathrm{m}^{2} / \mathrm{s}\right)$. Standard deviation was applied $(n=2)$. 
Based on the experimental evidence presented in this work, the most optimum favorable culturing conditions for Chlorella vulgaris growth within the microfluidic channels were $17.6 \mathrm{mM}$ and $80 \mu \mathrm{mol} / \mathrm{m}^{2} / \mathrm{s}$. These results are consistent with previous reports where the decreased growth of $C$. vulgaris has been reported at the lower nitrate concentration [10,43-45]. On the other hand, no significant decrease in C. vulgaris growth was reported with decreasing nitrate concentration [15]. To further optimize the effect of nitrate concentration on C. vulgaris growth rate, Jeanfils et al. established a limitation of linear relationship of the C. vulgaris growth rate with respect to the nitrate concentration [46].

Our results are in agreement with Kim et al., [47] who tested the influence of light intensity on Botryococcus braunii growth in a microfluidic device and found a 1.8-fold increase compared to bulk cultures. Moreover, our comparison investigations concurred with Dewan et al., [48] who investigated the growth kinetics of the microalgae, $C$. vulgaris, in immobilized arrays of nanoliter-scale microfluidic drops and found that the growth rates inside droplets were higher than bulk-scale experiments in most cases. Sung et al., reported the photoautotrophic growth of $C$. vulgaris after culturing cells for $120 \mathrm{~h}$ in a droplet-based photobioreactor; a round micropillar array. The growth kinetics were tested under different $\mathrm{CO}_{2}$ concentrations $(1 \%, 2.5 \%, 5 \%$, and $7.5 \%)$ and light intensities $(35,55,100,150$, and $200 \mu \mathrm{mol} / \mathrm{m}^{2} / \mathrm{s}$ ). The growth in a microdroplet showed better cell growth performance compared to a flask culture due to the reduced shading effects and improved mass transfer [49].

Our results are different from those reported by Kim et al., [50] where on-chip results were consistent with bulk culture results for Chlamydomonas reinhardtii cultured in an n-hexane-compatible lab-on-a-disc under nitrogen, acetic acid, and iron depletion. Kuntanawat et al. [51] studied the same growth habit of Spirulina platensis cultivated in both culturing systems. Chlamydomonas reinhardtii, Chlorella vulgaris, and Dunaliella tertiolecta growth were compared in a simple droplet-based microfluidic system and bulk cultures for 10 days. However, cell viability in the microfluidic device was lower than bulk cultures, and that the doubling time of microalgae grown in microdroplets was similar to growth in bulk [52]. C. vulgaris has been encapsulated inside $26 \mu \mathrm{m}$ droplets with alginate hydrogel microcapsules in a microwell array that incorporated a microbridge structure. A comparison of growth results with those of off-chip cultures demonstrated similar outcomes [21]. Our results were also different from Perin et al. [53], where microfluidic results were 10-fold lower than bulk cultures as a result of culturing Nannochloropsis gaditana under different light intensities $\left(6,60\right.$, or $\left.360 \mu \mathrm{mol} / \mathrm{m}^{2} / \mathrm{s}\right)$.

Since the growth rates of photoautotrophic organisms are highly dependent on the light intensity, comparing data for culturing systems indicated that the higher the nitrate concentration, the higher the growth rate under all tested light intensities (Table 1), whereas the growth inside the traditional system was higher than the droplet cultures due to the availability of the medium. All these experiments were performed from the same inoculant over the same time period (Figure 5).

Table 1. Maximum growth rates $\left(\mathrm{h}^{-1}\right)$ for $\mathrm{C}$. vulgaris cells cultured in BG11 medium with different nitrate concentrations of $4.4,8.8$, and $17.6 \mathrm{mM}$ for three days at $20^{\circ} \mathrm{C}$ and different light intensities of 20,80 , and $200 \mu \mathrm{mol} / \mathrm{m}^{2} / \mathrm{s}$ using traditional batch cultures and a microfluidic device.

\begin{tabular}{|c|c|c|c|}
\hline \multirow{2}{*}{$\begin{array}{l}\text { Light Intensity } \\
\left(\mu \mathrm{mol} / \mathrm{m}^{2} / \mathrm{s}\right)\end{array}$} & \multirow{2}{*}{$\begin{array}{l}\text { Nitrogen Condition } \\
\text { (mM) }\end{array}$} & \multicolumn{2}{|c|}{ Max. Growth Rate (per h) } \\
\hline & & $\begin{array}{l}\text { Microfluidic Culture } \\
\text { (mean/SD) }\end{array}$ & $\begin{array}{l}\text { Traditional Batch Culture } \\
\quad\left(\times 10^{4}\right)(\text { mean/SD })\end{array}$ \\
\hline \multirow{3}{*}{20} & 4.4 & $0.10 \pm 0.01$ & $0.06 \pm 0.002$ \\
\hline & 8.8 & $0.08 \pm 0$ & $0.12 \pm 0.02$ \\
\hline & 17.6 & $0.05 \pm 0.01$ & $0.12 \pm 0.006$ \\
\hline \multirow{3}{*}{80} & 4.4 & $0.10 \pm 0.01$ & $0.09 \pm 0$ \\
\hline & 8.8 & $0.07 \pm 0.04$ & $0.05 \pm 0.015$ \\
\hline & 17.6 & $0.27 \pm 0.05$ & $0.11 \pm 0.009$ \\
\hline \multirow{3}{*}{200} & 4.4 & $0.06 \pm 0.003$ & $0.06 \pm 0$ \\
\hline & 8.8 & $0.06 \pm 0.01$ & $0.05 \pm 0.007$ \\
\hline & 17.6 & $0.17 \pm 0.01$ & $0.09 \pm 0.01$ \\
\hline
\end{tabular}




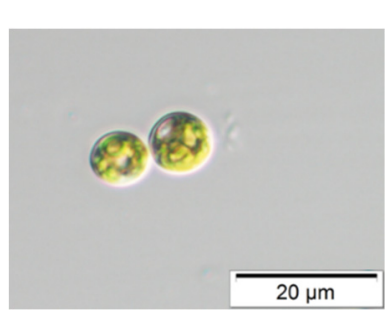

(a)

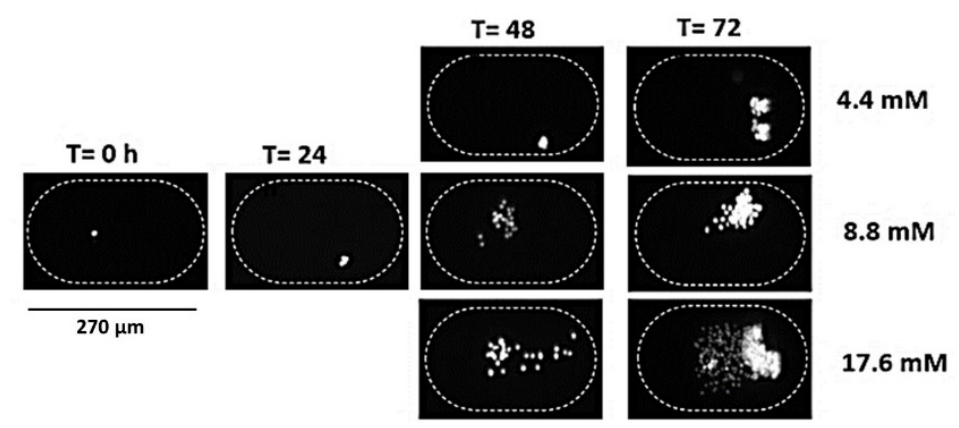

(b)

Figure 5. Chlorella vulgaris is a unicellular eukaryotic alga, spherical-shaped with a diameter of $3.32 \pm$ $0.99 \mu \mathrm{m}$. It has a single cup-shaped chloroplast. (a) Bright field image of C. vulgaris. (b) Time-lapse images of Chlorella vulgaris cells inside the microfluidic chambers at time $\mathrm{T}=0,24,48$, and $72 \mathrm{~h}$ after inoculation to show growth at $20{ }^{\circ} \mathrm{C}, 20 \mu \mathrm{mol} / \mathrm{m}^{2} / \mathrm{s}$, and different nitrate concentrations $(4.4,8.8$, and $17.6 \mathrm{mM})$. All these experiments were performed from the same inoculant over the same time period.

\section{Conclusions}

A microfluidic device was used as a low-cost, simple, and efficient solution for in vitro experiments to study the effects of different light intensities in combination with varying nitrogen availability on the growth rate of Chlorella vulgaris. The growth rates of photoautotrophic organisms are highly dependent on the light intensity. Comparing data for culturing systems indicated that the higher the nitrate concentration, the higher the growth rate under all tested light intensities, whereas the growth inside the conventional system was higher than the droplet cultures due to the availability of the medium. Based on the experimental evidence presented in this work, the most optimum favorable culturing conditions for Chlorella vulgaris growth within the microfluidic channels were $17.6 \mathrm{mM}$ and $80 \mu \mathrm{mol} / \mathrm{m}^{2} / \mathrm{s}$. We anticipate that the presented methodology can be extended for short-term in vitro experiments to examine multiple conditions under a variety of parameters to accelerate the strain selection process.

Supplementary Materials: The following are available online at http://www.mdpi.com/2218-273X/9/7/276/s1, Figure S1: Relationship between light over time represented from the data (A), and relation between uniform area $\left(\mathrm{cm}^{2}\right)$ and light intensity $\left(\mu \mathrm{mol} / \mathrm{m}^{2} / \mathrm{s}\right)(B)$. Where, $(C)$ Relationship between light over time represented from Northern Illinois University data. http://www.vernier.com/innovate/inverse-square-law-light-experimentmproved/. The consistency of light intensity over time was cleared. The lamp started with its highest power at zero time then its power was decreased until reached constant after $30 \mathrm{~min}$. Presented resulted agreed with Richard Borne results. He suggested an improvement to the Inverse Square Law Light Experiment using our Optics Expansion Kit; his suggestion is to turn on the LED light sources for a half hour or more before starting data collection because the intensity of white LED lamp decreases somewhat over time when it is first turned on (http://www.vernier.com/innovate/inverse-square-law-light-experiment-improved/).

Author Contributions: Conceptualization: M.G.S. and H.M.S.; methodology and analysis: M.G.S.; genetic identification: D.N.; writing—original draft preparation: M.G.S. and H.M.S.; writing—review and editing: M.G.S., N.S.D., M.S.K., M.S.Z., L.M., M.E.-B., D.N. and H.M.S.

Funding: This research was supported by the Egyptian Cultural affairs as a part of collaborated research done at Texas A\&M University.

Acknowledgments: The authors are grateful to Prof. Arum Han and Hyun Soo Kim for facilitating performing on-chip cultures. At the time of submission, N.S.D. is currently with Aromatic Plant Research Center, Lehi, UT, USA. M.S.K. is currently with University of Utah, Salt Lake City, UT, USA.

Conflicts of Interest: The authors declare no conflict of interest. 


\section{References}

1. Kellam, S.J.; Walker, J.M. Antibacterial activity from marine microalgae in laboratory culture. Br. Phycol. J. 1989, 24, 191-194. [CrossRef]

2. Maadane, A.; Merghoub, N.; El Mernissi, N.; Ainane, T.; Amzazi, S. Antimicrobial activity of marine microalgae isolated from moroccan coastlines. J. Microbiol. Biotechnol. Food Sci. 2017, 6, 1257-1260. [CrossRef]

3. Burkholder, P.R.; Burkholder, L.M.; Almodovar, L.R. Antibiotic activity of some marine algae of Puerto Rico. Bot. Mar. 1960, 2, 149-156. [CrossRef]

4. Demirbas, A. Use of algae as biofuel sources. Energy Convers. Manag. 2010, 51, 2738-2749. [CrossRef]

5. Saad, M.G.; Dosoky, N.S.; Zoromba, M.S.; Shafik, H.M. Algal Biofuels: Current Status and Key Challenges. Energies 2019, 12, 1920. [CrossRef]

6. Raheem, A.; Prinsen, P.; Vuppaladadiyam, A.K.; Zhao, M.; Luque, R. A review on sustainable microalgae based biofuel and bioenergy production: Recent developments. J. Clean. Prod. 2018, 181, 42-59. [CrossRef]

7. Priyadarshani, I.; Rath, B. Commercial and industrial applications of micro algae-A review. J. Algal Biomass Utln. 2012, 3, 89-100.

8. Schnurr, P.J.; Allen, D.G. Factors affecting algae biofilm growth and lipid production: A review. Renew. Sustain. Energy Rev. 2015, 52, 418-429. [CrossRef]

9. Wahidin, S.; Idris, A.; Shaleh, S.R.M. The influence of light intensity and photoperiod on the growth and lipid content of microalgae Nannochloropsis sp. Bioresour. Technol. 2013, 129, 7-11. [CrossRef]

10. Lv, J.M.; Cheng, L.H.; Xu, X.H.; Zhang, L.; Chen, H.L. Enhanced lipid production of Chlorella vulgaris by adjustment of cultivation conditions. Bioresour. Technol. 2010, 101, 6797-6804. [CrossRef]

11. Grima, E.M.; Belarbi, E.H.; Fernández, F.A.; Medina, A.R.; Chisti, Y. Recovery of microalgal biomass and metabolites: Process options and economics. Biotechnol. Adv. 2003, 20, 491-515. [CrossRef]

12. Deenu, A.; Naruenartwongsakul, S.; Kim, S.M. Optimization and economic evaluation of ultrasound extraction of lutein from Chlorella vulgaris. Biotechnol. Bioprocess Eng. 2013, 18, 1151-1162. [CrossRef]

13. Pratt, R.; Daniels, T.C.; Eiler, J.J.; Gunnison, J.B.; Kumler, W.D.; Oneto, J.F.; Strait, L.A.; Spoehr, H.A.; Hardin, G.J.; Milner, H.W.; et al. Chlorellin, an antibacterial substance from Chlorella. Science 1944, 351-352. [CrossRef] [PubMed]

14. Lee, J.H.; Lee, J.S.; Shin, C.S.; Park, S.C.; Kim, S.W. Effects of $\mathrm{NO}$ and $\mathrm{SO}_{2}$ on growth of highly-CO ${ }_{2}$,-tolerant microalgae. J. Microbiol. Biotechnol. 2000, 10, 338-343.

15. Converti, A.; Casazza, A.A.; Ortiz, E.Y.; Perego, P.; Borghi, M. Del Effect of temperature and nitrogen concentration on the growth and lipid content of Nannochloropsis oculata and Chlorella vulgaris for biodiesel production. Chem. Eng. Process. 2009, 48, 1146-1151. [CrossRef]

16. Mayo, A.W. Effects of temperature and $\mathrm{pH}$ on the kinetic growth of unialga Chlorella vulgaris cultures containing bacteria. Water Environ. Res. 1997, 69, 6472. [CrossRef]

17. Szita, N.; Boccazzi, P.; Zhang, Z.; Boyle, P.; Sinskey, A.J.; Jensen, K.F. Development of a multiplexed microbioreactor system for high-throughput bioprocessing. Lab Chip 2005, 5, 819-826. [CrossRef]

18. Sung, Y.J.; Kim, J.Y.H.; Choi, H.I.; Kwak, H.S.; Sim, S.J. Magnetophoretic sorting of microdroplets with different microalgal cell densities for rapid isolation of fast-growing strains. Sci. Rep. 2017, 7, 10390. [CrossRef]

19. Deng, Y.L.; Kuo, M.Y.; Juang, Y.J. Development of flow through dielectrophoresis microfluidic chips for biofuel production: Sorting and detection of microalgae with different lipid contents. Biomicrofluidics 2014, 8, 064120. [CrossRef]

20. Kwak, H.S.; Kim, J.Y.; Na, S.C.; Jeon, N.L.; Sim, S.J. Multiplex microfluidic system integrating sequential operations of microalgal lipid production. Analyst 2016, 141, 1218-1225. [CrossRef]

21. Lee, D.H.; Bae, C.Y.; Han, J.I.; Park, J.K. In situ analysis of heterogeneity in the lipid content of single green microalgae in alginate hydrogel microcapsules. Anal. Chem. 2013, 85, 8749-8756. [CrossRef] [PubMed]

22. Bodénès, P.; Wang, H.Y.; Lee, T.H.; Chen, H.Y.; Wang, C.Y. Biotechnology for Biofuels Microfluidic techniques for enhancing biofuel and biorefinery industry based on microalgae. Biotechnol. Biofuels 2019, 1-25. [CrossRef]

23. Zheng, G.X.; Li, Y.J.; Qi, L.L.; Liu, X.M.; Wang, H.; Yu, S.P.; Wang, Y.H. Marine phytoplankton motility sensor integrated into a microfluidic chip for high-throughput pollutant toxicity assessment. Mar. Pollut. Bull. 2014, 84, 147-154. [CrossRef] [PubMed] 
24. Rhituparna Payel, P. Lab on a Chip systems for environmental analysis. Master's Thesis, University of Stavanger, Stavanger, Norway, 2014.

25. Yang, Y.T.; Wang, C. Review of microfluidic photobioreactor technology for metabolic engineering and synthetic biology of cyanobacteria and microalgae. Micromachines 2016, 7, 185. [CrossRef] [PubMed]

26. Abgrall, P.; Gue, A.-M. lab-on-chip technologies: Making a microfluidic network and coupling it into a complete microsystem-A review. J. Micromech. Microeng. 2007, 17, R15-R49. [CrossRef]

27. BG-11 Medium. Available online: https://utex.org/products/bg-11-medium (accessed on 6 March 2019).

28. Fawley, M.W.; Fawley, K.P.; Buchheim, M.A. Molecular diversity among communities of freshwater microchlorophytes. Microb. Ecol. 2004, 48, 489-499. [CrossRef]

29. Del Campo, E.M.; del Hoyo, A.; Royo, C.; Casano, L.M.; Álvarez, R.; Barreno, E. A single primer pair gives a specific ortholog amplicon in a wide range of Cyanobacteria and plastid-bearing organisms: Applicability in inventory of reference material from collections and phylogenetic analysis. Mol. Phylogenet. Evol. 2010, 57, 1323-1328. [CrossRef]

30. Kim, H.S.; Waqued, S.C.; Nodurft, D.T.; Devarenne, T.P.; Yakovlev, V.V.; Han, A. Raman spectroscopy compatible PDMS droplet microfluidic culture and analysis platform towards on-chip lipidomics. Analyst 2017, 142, 1054-1060. [CrossRef]

31. Abràmoff, M.D.; Magalhães, P.J.; Ram, S.J. Image processing with Image J. Biophotonics Int. 2004, 11, $36-42$.

32. Issarapayup, K.; Powtongsook, S.; Pavasant, P. Flat panel airlift photobioreactors for cultivation of vegetative cells of microalga Haematococcus pluvialis. J. Biotechnol. 2009, 142, 227-232. [CrossRef]

33. Absher, M. Hemocytometer counting. In Tissue Culture: Methods and Applications; Academic Press: New York, NY, USA, 1973; pp. 395-397.

34. Wheeler, P.A.; Kokkinakis, S.A. Ammonium recycling limits nitrate use in the oceanic subarctic Pacific. Limnol. Oceanogr. 1990, 35, 1267-1278. [CrossRef]

35. Shafik, H.M.; Saad, M.G.; El-Serehy, H.A. Impact of nitrogen regime on fatty acid profiles of Desmodesmus quadricaudatus and Chlorella sp. and ability to produce biofuel. Acta Bot. Hung. 2015, 57, 205-218. [CrossRef]

36. Ogbonna, J.C.; Masui, H.; Tanaka, H. Sequential heterotrophic/autotrophic cultivation - An efficient method of producing Chlorella biomass for health food and animal feed. J. Appl. Phycol. 1997, 9, 359-366. [CrossRef]

37. Yun, Y.S.; Park, J.M. Attenuation of monochromatic and polychromatic lights in Chlorella vulgaris suspensions. Appl. Microbiol. Biotechnol. 2001, 55, 765-770. [CrossRef] [PubMed]

38. Cepak, V.; Pribyl, P.; Vitova, M. The effect of light color on the nucleocytoplasmic and chloroplast cycle of the green chlorococcal alga Scenedesmus obliquus. Folia Microbiol. (Praha) 2006, 51, 342-348. [CrossRef] [PubMed]

39. Nguyen, B.; Graham, P.J.; Sinton, D. Dual gradients of light intensity and nutrient concentration for full-factorial mapping of photosynthetic productivity. Lab Chip 2016, 16, 2785-2790. [CrossRef] [PubMed]

40. Van Wagenen, J.; Miller, T.W.; Hobbs, S.; Hook, P.; Crowe, B.; Huesemann, M. Effects of light and temperature on fatty acid production in Nannochloropsis salina. Energies 2012, 5, 731-740. [CrossRef]

41. Kautsky, H.; Hirsch, A. Neue versuche zur kohlensäureassimilation. Naturwissenschaften 1931, $19,964$. [CrossRef]

42. Erickson, R.A.; Jimenez, R. Microfluidic cytometer for high-throughput measurement of photosynthetic characteristics and lipid accumulation in individual algal cells. Lab Chip 2013, 13, 2893-2901. [CrossRef]

43. Daliry, S.; Hallajsani, A.; Mohammadi Roshandeh, J.; Nouri, H.; Golzary, A. Investigation of optimal condition for Chlorella vulgaris microalgae growth. Glob. J. Environ. Sci. Manag. 2017, 3, 217-230.

44. Liu, Z.Y.; Wang, G.C.; Zhou, B.C. Effect of iron on growth and lipid accumulation in Chlorella vulgaris. Bioresour. Technol. 2008, 99, 4717-4722. [CrossRef] [PubMed]

45. Scarsella, M.; Belotti, G.; De Filippis, P.; Bravi, M. Study on the optimal growing conditions of Chlorella vulgaris in bubble column photobioreactors. Chem. Eng. 2010, 20, 85-90.

46. Jeanfils, J.; Canisius, M.F.; Burlion, N. Effect of high nitrate concentrations on growth and nitrate uptake by free-living and immobilized Chlorella vulgaris cells. J. Appl. Phycol. 1993, 5, 369-374. [CrossRef]

47. Kim, H.S.; Weiss, T.L.; Thapa, H.R.; Devarenne, T.P.; Han, A. A microfluidic photobioreactor array demonstrating high-throughput screening for microalgal oil production. Lab Chip 2014, 14, 1415-1425. [CrossRef] [PubMed] 
48. Dewan, A.; Kim, J.; McLean, R.H.; Vanapalli, S.A.; Karim, M.N. Growth kinetics of microalgae in microfluidic static droplet arrays. Biotechnol. Bioeng. 2012, 109, 2987-2996. [CrossRef] [PubMed]

49. Sung, Y.J.; Kim, J.Y.; Bong, K.W.; Sim, S.J. Microdroplet photobioreactor for the photoautotrophic culture of microalgal cells. Analyst 2016, 141, 989-998. [CrossRef] [PubMed]

50. Kim, Y.; Jeong, S.N.; Kim, B.; Kim, D.P.; Cho, Y.K. Rapid and automated quantification of microalgal lipids on a spinning disc. Anal. Chem. 2015, 87, 7865-7871. [CrossRef]

51. Kuntanawat, P.; Ruenin, J.; Phatthanakun, R.; Kunhorm, P.; Surareungchai, W.; Sukprasong, S.; Chomnawang, N. An electrostatic microwell-based biochip for phytoplanktonic cell trapping. Biomicrofluidics 2014, 8, 034108. [CrossRef]

52. Pan, J.; Stephenson, A.L.; Kazamia, E.; Huck, W.T.; Dennis, J.S.; Smith, A.G.; Abell, C. Quantitative tracking of the growth of individual algal cells in microdroplet compartments. Integr. Biol. 2011, 3, 1043-1051. [CrossRef]

53. Perin, G.; Cimetta, E.; Monetti, F.; Morosinotto, T.; Bezzo, F. Novel micro-photobioreactor design and monitoring method for assessing microalgae response to light intensity. Algal Res. 2016, 19, 69-76. [CrossRef]

(C) 2019 by the authors. Licensee MDPI, Basel, Switzerland. This article is an open access article distributed under the terms and conditions of the Creative Commons Attribution (CC BY) license (http://creativecommons.org/licenses/by/4.0/). 